\title{
Cadeira de rodas e acessórios para adequação postural na paralisia cerebral: Uma análise documental
}

\author{
Maria Alice Alvarenga Duarte Campos \\ Terapeuta ocupacional, Formação em Conceito Bobath, Especialista em Tecnologia Assistiva, \\ Coordenadora técnica da Postural Equipamentos Terapêuticos Ltda, Salvador, BA, Brasil
}

\begin{abstract}
Resumo: Cadeira de rodas ou carrinho de transporte com sistemas de assentos diferenciados são indicados para uma parcela considerável da população que possui a paralisia cerebral. Na prescrição adequada destes, o terapeuta ocupacional deve atender as necessidades de posicionamento, conforto, segurança e mobilidade funcional. Um serviço de sistemas de adequação da postura sentada especializado para essa população foi desenvolvido no estado da Bahia. O objetivo deste é apresentar os resultados do processo que vem sendo desenvolvido há cerca de dez anos, a partir da análise documental das fichas do serviço. Foram identificadas 40 fichas de acordo com os critérios de inclusão. A análise dos dados ocorreu através de estatística descritiva. As fichas analisadas apontaram que houve intervenção em 51 equipamentos, sendo 45 (88\%) eram cadeiras de rodas e $6(12 \%)$ em carrinhos de bebê. Os acessórios estavam presentes na maioria dos equipamentos, e foram ajustados personalizados a cada caso.
\end{abstract}

Palavras-chave: Paralisia Cerebral, Posicionamento do Paciente, Equipamentos de Autoajuda.

\section{Wheelchair and devices for seating positioning in cerebral palsy: A documentary review}

\begin{abstract}
Wheelchairs or prams with adaptations are recommended for a considerable portion of the population with cerebral palsy. In prescribing such equipment, occupational therapists must consider the needs of positioning, comfort, safety, and functional mobility. A system was developed for such specialized seating in the state of Bahia. The purpose of this study is to present the outcomes of the process being developed for about ten years, using evidence from the documentary analysis of the service records. We identified 40 case notes that applied the inclusion criteria. Data analysis was performed by descriptive statistics. The notes were analyzed and indicated that were interventions in 51 devices, including 45 (88\%) wheelchairs and $6(12 \%)$ prams. Accessories were present in most pieces of equipment and were custom made to each case.
\end{abstract}

Keywords: Cerebral Palsy, Patient Positioning, Self-help Devices.

\section{Introdução}

Uma parcela considerável da população que possui a paralisia cerebral como diagnóstico clínico necessita de cadeira de rodas ou carrinho de transporte com sistemas de assentos diferenciados. Para uma prescrição adequada desses equipamentos, o terapeuta ocupacional utiliza recursos tecnológicos para atender as necessidades de posicionamento e alcançar conforto, segurança e mobilidade funcional (CAVALCANTI; GALVÃO; CAMPOS, 2007).

No geral, uma cadeira de rodas ou um carrinho de transporte possuem como sistema postural um assento almofadado como base para a estabilidade 
da pelve e um encosto para o tronco. Além de componentes adicionais que conferem ao usuário o conforto necessário, como o apoio de cabeça/pés/ braços, os estabilizadores de tronco, as especialidades para inclinação do assento e/ou do encosto (REIS, 2004).

Quando a intervenção no equipamento consiste em cadeira de rodas ou carrinho de transporte com sistemas de assentos diferenciados, os acessórios e as almofadas originais podem ser aproveitados para transformaçóes específicas ou ainda totalmente projetados de forma personalizada, envolvendo o trabalho profissional entre técnicos especializados e o terapeuta ocupacional.

De acordo com Cavalcanti, Galvão e Campos (2007, p. 458):

$\mathrm{Na}$ elaboração de um equipamento desse tipo, são requeridas etapas organizadas e sequenciadas que constam de consulta inicial, avaliaçâo do cliente e de suas habilidades, avaliação do equipamento de base, planejamento e desenvolvimento do projeto, contato com os técnicos e profissionais envolvidos, corte e modelagem de espumas, prova do equipamento, ajustes e prescrição de acessórios, capotagem, entrega da cadeira, orientaçóes para uso e agendamento do retorno para revisão.

Quando se tratando de criança com diagnóstico de paralisia cerebral, Zollars e Knezevich (1996) registra que é necessário suporte para controle postural e de membros superiores. E que uma postura sentada adequada pode facilitar atividades como alimentação, respiração, comunicação, socialização e aprendizado.

O processo de encaminhamento de um paciente com diagnóstico de paralisia cerebral para aquisição de um sistema de adequação da postura sentada deve ser assim que seja detectada essa necessidade, uma vez que esse sistema contribuirá para a organização da postura e do movimento e controle das deformidades (RODBY-BOUSQUET; HÄGGLUND, 2010).

Uma consulta ao profissional especializado facilita a escolha da cadeira de rodas e dos acessórios. Ele realizará entrevista (anamnese) durante a qual investiga experiências e necessidades individuais. E, para a indicação correta de dispositivo para adequação da postura sentada, o uso de medidas antropométricas é fator fundamental na avaliação postural e biomecânica. A capacidade funcional, a percepção, a visão, os objetivos do usuário/cuidador e os locais onde o equipamento será mais utilizado são também englobados no processo final de escolha (PALISANO et al., 2003).
Um serviço especializado para essa população foi desenvolvido no estado da Bahia, com coordenaçáo de terapeuta ocupacional direcionado a essa população em tecnologia assistiva, cuja prática clínica é voltada para o desenvolvimento e produção de sistemas de adequação da postura sentada diferenciados. Assim, o objetivo deste estudo é apresentar os resultados desse serviço que vem sendo desenvolvido há dez anos.

\section{Percurso metodológico}

Este estudo é classificado como retrospectivo exploratório e descritivo, de natureza quantitativa, onde a pesquisa documental foi o procedimento de delineamento utilizado (GIL, 2006). Os dados foram coletados através das fichas de avaliação de um serviço de terapia ocupacional, em uma clínica de adequação postural sentada, no estado da Bahia, coordenada por terapeuta ocupacional especialista em tecnologia assistiva, com atuaçáo na área de adequaçáo da postura sentada - seating e positioning.

Os dados coletados nas fichas de avaliação do serviço foram transcritos para um formulário padrão para posterior análise e quantificação; e englobaram as variáveis em duas perspectivas. A primeira referente às características dos clientes, sendo coletadas informaçôes sobre o gênero, a idade e o tipo de paralisia cerebral. E, após determinar a quantidade de cadeiras de rodas e de carrinho de bebê, a segunda centralizou informaçóes específicas sobre o equipamento cadeira de rodas no que se refere: (a) ao tipo de cadeira de rodas, se manual ou motorizada; (b) à especialização do sistema de inclinação do assento/encosto; (c) ao tempo de revisão; (d) ao tipo de almofada; (e) à presença de apoio de cabeça; (f) à indicação de faixas e cintos; $(\mathrm{g})$ às contençôes do tronco; $(\mathrm{h})$ à presença de adutor e abdutor; (i) à indicaçấo de mesa de atividades; e (j) à constância de apoio de pés.

Foram selecionadas as fichas que atendiam aos seguintes critérios:

- Eram de clientes com diagnóstico de paralisia cerebral;

- Eram registros no período de 2003 a 2011;

- E tinham indicação de equipamento para adequaçáo da postura sentada.

A análise foi através de estatística descritiva (frequência absoluta e relativa).

\section{Resultados e discussão}

De acordo com os critérios de inclusão foram selecionadas para este estudo 40 fichas de avaliação 
de pacientes com diagnóstico de paralisia cerebral acompanhados no período de 2003 a 2011. Destes 20 foram do sexo masculino e 20 do sexo feminino, com idade variando entre 11 meses e 33 anos. E a classificação pelo quadro clínico de paralisia cerebral: 19 (48\%) fichas eram de usuários com tetraparesia espástica; 15 (38\%) do tipo misto; 3 (8\%) com diparesia espástica; 2 (5\%) hipotônicos e 1 (1\%) do tipo coreico (Tabela 1).

As fichas analisadas apontaram que houve intervenção em 51 equipamentos. Destes, 45 (88\%) eram cadeiras de rodas e $6(12 \%)$ eram carrinhos de bebê. Para Cooper et al. (2008), existe uma diversidade de modelos de cadeira de rodas no mercado e estas diferem em alguns aspectos básicos, como o tipo de material usado na fabricação da estrutura, a forma de dirigibilidade (manual ou motorizada), as possibilidades de fechamento e de inclinação.

Partindo para uma análise detalhada do grupo das cadeiras de rodas selecionadas, temos os resultados a seguir (Tabela 2).

Das cadeiras de rodas $43(96 \%)$ eram manuais e 2 (4\%) com motorização. Os sistemas de inclinação (tilt ou recline) estavam presentes em 35 (69\%) desses equipamentos, sendo 16 (46\%) com tilt, 9 (26\%) com reclínio e 10 (28\%) a combinação de ambos.

As indicaçóes para especializaçấo do conjunto assento-encosto estavam justificadas pelo comprometimento motor e cognitivo do grupo. A análise das fichas de avaliação apontava limitaçâo no controle da postura sentada, necessidade de variação dessa postura através do dispositivo, uma

Tabela 1. Características dos clientes $(n=40)$.

\begin{tabular}{llr}
\hline \multicolumn{1}{c}{ Variável } & Subgrupo & \multicolumn{1}{c}{$\mathbf{n}(\%)$} \\
\hline \multirow{2}{*}{ Gênero } & Masculino & $20(50,0)$ \\
& Feminino & $20(50,0)$ \\
\hline & $0-1$ & $3(7,5)$ \\
& $2-5$ & $9(22,5)$ \\
Idade (emanos) & $6-10$ & $11(27,5)$ \\
Média = 10,6 & $11-15$ & $8(20,0)$ \\
& $16-20$ & $6(15,0)$ \\
& $21-25$ & $2(5,0)$ \\
& $26-30$ & $0(0)$ \\
& $31-35$ & $1(2,5)$ \\
\hline & Tetraparesia & $19(48,0)$ \\
& Misto & $15(38,0)$ \\
Classificação da PC & Diparesia & $3(8,0)$ \\
& Hipotônicos & $2(5,0)$ \\
& Coreico & $1(1,0)$ \\
\hline
\end{tabular}

vez que os ajustes corporais dos usuários não eram possíveis de forma independente.

As possibilidades de inclinaçáo do sistema de adequação postural sentada contribuem para uma distribuição melhor da pressão, controle da postura e do movimento,otimizando o tempo de uso do equipamento e a funcionalidade do usuário. Essa característica do sistema o torna mais confortável e é importante de se considerar, principalmente em crianças que passam mais tempo sentadas e têm dificuldade de mover seu corpo. Se a criança está desconfortável, ela provavelmente chora, fica ansiosa, quer ficar em pé ou mover-se buscando conforto. Esses movimentos podem se tornar um problema, pois podem impedir o desempenho de funçôes (ENGSTRÖM, 2002).

Segundo Batista (2004), o trabalho antigravitacional possibilitado pela inclinaçáo do sistema assento/encosto deve ocorrer gradativamente, com auxílio de equipamento dinâmico. Conforme a evolução do quadro clínico é indicado reduzir a inclinação do mesmo com o objetivo de estimular a ativação muscular e manter o paciente em uma posição mais funcional. Para diversos usuários um sistema dinâmico é benéfico, pois permite mudanças de posição entre atividades e descanso (ENGSTRÖM, 2002).

No que se refere ao processo de acompanhamento do equipamento, das 40 fichas selecionadas $24(60 \%)$ registravam o retorno para reavaliaçóes do sistema

Tabela 2. Características das cadeiras de rodas $(\mathrm{n}=47)$.

\begin{tabular}{llr}
\hline \multicolumn{1}{c}{ Variável } & Subgrupo & \multicolumn{1}{c}{ n (\%) } \\
\hline \multirow{2}{*}{ Tipo de cadeira de rodas } & Manual & $43(96,0)$ \\
& Motorizada & $2(4,0)$ \\
\hline \multirow{3}{*}{ Sistema de inclinação } & Tilt & $16(46,0)$ \\
& Recline & $9(26,0)$ \\
& Tilt-recline & $10(28,0)$ \\
\hline \multirow{2}{*}{ Apoio de cabeça } & Presente & $33(65,0)$ \\
& Ausente & $18(35,0)$ \\
\hline \multirow{2}{*}{ Cintos e faixas } & Presente & $48(94,0)$ \\
& Ausente & $3(6,0)$ \\
\hline \multirow{2}{*}{ Contenção do tronco } & Presente & $49(96,0)$ \\
& Ausente & $2(4,0)$ \\
\hline \multirow{2}{*}{ Acessório adutor } & Presente & $39(76,0)$ \\
& Ausente & $12(24,0)$ \\
\hline \multirow{2}{*}{ Acessório abdutor } & Presente & $32(63,0)$ \\
& Ausente & $19(36,0)$ \\
\hline \multirow{2}{*}{ Mesa de atividades } & Presente & $33(65,0)$ \\
& Ausente & $18(35,0)$ \\
\hline
\end{tabular}


de adequação postural sentada, sendo que dessas $15(62,5 \%)$ apontavam como procedimento padrão os ajustes do sistema e 9 (37,5\%), além dos ajustes, a aquisição breve de nova cadeira.

Um equipamento ou dispositivo é adequado por um determinado período, mas sua eficácia pode ser perdida com o tempo, em função do crescimento do usuário, mudanças no quadro clínico, uma demanda ortopédica ou outros fatores relacionados com o desenvolvimento (WRIGHT; CASEY; PORTERARMSTRONG, 2010).

De acordo com Cavalcanti, Galvão e Campos (2007), o ideal é que a revisão seja mantida com uma periodicidade semestral. Porém, observou-se que para aqueles com idade compreendida entre 7 meses e 2 anos, aproximadamente, o período dos ajustes diminuiu chegando a ocorrer em intervalos trimestrais.

Quanto aos acessórios, não serão mencionadas as almofadas de assento e encosto, pois exigem um estudo à parte pela importância e extensão do assunto. A variedade desses produtos no mercado é grande e as indicações são específicas. Mas destaca-se que todos os equipamentos citados (100\%) receberam almofadas modeladas de forma individualizada. Tal preferência se deu pela necessidade dos usuários e pela análise realizada durante as provas, concluindo que as modelagens resultavam em melhor correção e/ou acomodaçáo da postura sentada.

Ainda, quanto às almofadas, destaca-se a importância por parte do terapeuta na escolha adequada do tipo de espuma a ser usada, de sua capacidade de imersão e dureza nas áreas de maior pressão e a escolha apropriada do material usado como invólucro.

$\mathrm{Na}$ análise das características dos acessórios utilizados, o apoio de cabeça, indicado para o posicionamento e suporte de uma cabeça instável, foi verificado nas fichas de quadro clínico de paralisia com um controle cervical ausente ou incompleto, registrando-se que o posicionamento inadequado da cabeça interfere em diversas funçôes (FUHRMAN; KARG; BERTOCCI, 2008).

Assim, dos 51 equipamentos apontados nas 40 fichas selecionadas, 33 (65\%) tinham o acessório apoio de cabeça. Destes, 7 (21\%) eram no formato em $\mathrm{C}$ ou planar, que podem ser adquiridos no mercado, e 26 (79\%) necessitaram de modelagem personalizada devido à assimetria da cabeça e/ou à tendência para se manter em inclinação anterior ou em rotaçáo para um lado do corpo. Nestes foi necessária a indicação de um apoio de cabeça personalizado com uma profundidade maior em um dos lados de apoio.

Para Engström (2002), alguns estabilizadores são simples e sem reajustes, outros podem apresentar diversos sistemas de ajustes, permitindo que a cabeça fique estabilizada com adequada qualidade para campo visual, além do desenvolvimento de atividades através da coordenação dos movimentos oculares e visuomanual.

Em uma segunda análise dos apoios de cabeça personalizados verificou-se que dos 26 apoios, 12 (46\%) acompanhavam suporte cervical. O suporte cervical é usado como uma forma de prolongamento do apoio de cabeça proporcionando maior área de contato e conforto. A adaptação do acessório foi feita sob medida em espuma e fixada ao apoio de cabeça através de velcro de forma a facilitar a remoção. Quando em associação aos sistemas de inclinação (tilt e/ou recline), é útil no controle do tônus muscular, na acomodação e estabilidade da cabeça/pescoço. Funcionalmente Fuhrman, Karg e Bertocci (2008) apontam que o acessório permite melhora das funções de deglutição, respiração, atividade manual e comunicação.

Larnet e Ekberg (1995) citam que lesôes neurológicas podem causar anormalidades na atividade motora oral e transtornos na coordenaçáo da deglutição. Várias dessas crianças são hipotônicas no tronco. Quando sustentadas em posição sentada, entretanto, a coluna torna-se cifótica e a espinha cervical com acentuada lordose. Assim, a criança normalmente tem um pobre controle labial e um transporte inadequado do bolo alimentar na cavidade oral. Isso leva ao vazamento anterior do conteúdo oral para fora da boca. Devido a isso, a cabeça está normalmente inclinada para trás. A criança, portanto, estende o pescoço, sendo que tal postura tem uma influência negativa na função da faringe durante a deglutição.

Ainda, Silva e Reis (2004) relatam que a comunicação que muitas vezes está limitada pode se tornar mais funcional com a cabeça bem posicionada. Na paralisia cerebral é necessário estabelecer uma possibilidade de retorno para o ato comunicativo. Essa possibilidade pode ser alcançada definindo um equipamento para posicionamento e utilizando recursos de comunicação suplementar e/ ou alternativa.

Outro acessório frequentemente utilizado no seating e positioning nos casos de paralisia cerebral são as faixas e os cintos.Juntamente com outros suportes são acessórios que contribuem para a manutenção da postura da pélvis e do tronco, na cadeira de rodas 
ou carrinho de bebê, e proporcionam segurança. A indicação e o uso destes devem ser cuidadosos para não oferecer desconforto e risco de compressão. Portanto é recomendado utilizar faixas mais largas, acolchoadas, e o cuidador deve ser treinado para saber utilizá-las.

Apenas $3(6 \%)$ das cadeiras analisadas não necessitaram de cinto pélvico, sendo que 35 (69\%) receberam o modelo 4 pontos. Este modelo são duas faixas que saem de dentro da espuma do assento passando entre as pernas em sentido diagonal, puxando a pélvis para trás de forma a garantir o posicionamento da mesma o mais próximo possível do encosto. Cada uma dessas faixas se prende por meio de velcro em outras duas que saem de cada lado do encosto.

Dos outros modelos de cinto pélvico utilizados, $10(20 \%)$ equipamentos usaram o modelo calção e $3(6 \%)$ o modelo 4 pontos, juntamente com uma faixa horizontal. O modelo calção é mais indicado para crianças menores, pois o design é similar a uma fralda. $\mathrm{O}$ uso de dois cintos é mais indicado nos casos em que predomina forte movimentação involuntária associada ao tônus extensor, sendo necessário distribuir os pontos de força de maneira mais uniforme.

Cook e Polgar (2007) sugerem que o cinto pélvico forme um ângulo de $45^{\circ} \mathrm{com}$ o assento e que um segundo cinto na crista ilíaca antero superior da pélvis do paciente poderá ajudar a posicioná-la para trás e em posição neutra.

Os cintos e faixas para tronco foram usados em 41 (80\%) dos equipamentos, sendo o modelo mais comum o cinto tipo colete ou borboleta. Esse modelo oferece maior área de apoio, auxilia no posicionamento dos ombros e consequentemente ajuda na manutenção da postura da cabeça. Assim o usuário pode está mais apto ao contato social e a participar de atividades.

Engström (2002, p. 199) cita que "[...] a posição adequada para o tronco é um dos estímulos para a performance natural das mãos ativamente funcionais [...]" e que o cinto peitoral, os suportes laterais e a mesa servem como apoio oferecendo estabilidade e liberdade para outras partes do corpo serem mais ativas. Além disso, o alinhamento da coluna com o uso desses acessórios e a capacidade do sistema de ser modificado ao longo do dia favorecem alternância entre atividade, relaxamento e descanso.

Dos outros 10 equipamentos, 5 (10\%) receberam modelos variados de cinto para o tronco, dentre eles faixas na direção horizontal, em diagonal e nos formatos de $\mathrm{H}$, Y e X conforme necessidade individual, e os outros 5 (10\%) náo necessitaram desse tipo de acessório.

Dos 51 equipamentos analisados, 31 (61\%) receberam contençôes de tronco rebatíveis e reguláveis e 18 (35\%) fixas produzidas em alumínio com espuma. Apenas dois (4\%) equipamentos não receberam suporte para o tronco após reavaliação e aquisição de nova cadeira de rodas. Todas as contençōes indicadas foram para maior sustentação, uma vez que os pacientes apresentavam um grau de escoliose considerável, porém flexível ou necessitavam manter a correção estrutural da coluna (pós-cirúrgico).

As contençôes de tronco ou suportes para o tronco são normalmente confeccionadas em espuma ou uma peça formada com alumínio e espuma. A primeira é mais usada nos casos em que a assimetria de tronco é facilmente corrigida ou apenas para dar um feedback sensorial para o endireitamento da postura, podendo ser fixada com velcro ao encosto ou associada ao encosto anatômico. A segunda por ser mais resistente é indicada quando a aplicação de força faz-se necessária, como nos casos para correção de uma escoliose. Essa força deve ser aplicada em pontos predeterminados em avaliação e testados durante a prova do equipamento. É importante avaliar a tolerância do paciente às correçôes, respeitando suas limitaçóes. Esse modelo pode apresentar-se fixo ao encosto pode ser rebatível e/ou ter ajustes de altura, largura e profundidade.

$\mathrm{Na}$ análise, 39 equipamentos $(76 \%)$ receberam adutores e dentre estes $2(5 \%)$ foram faixas adutoras, mais indicadas nos casos em que a correção é possível com aplicação de menor força, 24 (62\%) com adutores reforçados e 13 (33\%) com espuma modelada.

E, com relação aos abdutores, 32 (63\%) foram contabilizados, sendo 17 (33\%) do tipo reforçado e 15 (29\%) do modelo em espuma. Observou-se que as contençóes de quadril (adutor e abdutor) reforçadas foram as mais utilizadas devido ao comprometimento dos pacientes com tendência a posiçôes deformantes de quadril.

Os adutores e abdutores são acessórios usados para o alinhamento do quadril que se apresenta em posiçóes deformantes (adução, abdução, posição em "ventania"). A posição correta do quadril quando sentado, além de prevenir deformidades contribui para o melhor alinhamento do tronco (COOK; POLGAR, 2007). Esses dispositivos geralmente são em forma de faixas, que devem ser largas, acolchoadas e não devem limitar a movimentaçáo, podem ser feitos em espumas ou serem peças reforçadas em alumínio 
com espuma. Esses acessórios devem ser associados ao assento respeitando os limites de correção.

Um abdutor deve ser colocado próximo aos joelhos e 1/3 distal da coxa, enquanto um adutor segue a mesma disposição e localizam-se nas laterais do assento (CAVALCANTI; GALVÁO; CAMPOS, 2007).

A mesa de atividades é outro acessório também utilizado como um importante apoio que auxilia na extensão e estabilidade do tronco, na sustentação dos membros superiores, posicionando os ombros, os braços e mãos, facilitando atividades como a alimentação, a escrita, a leitura e o brincar (ANTONELI, 2003).

Podendo ser confeccionada em vários materiais, as mais comuns são as produzidas em madeira que podem ser acolchoadas ou não, e as mesas em acrílico. Como característica, essas mesas de atividades possuem um recorte para encaixe do tronco e geralmente são feitas com bordas elevadas nas laterais, de forma a impedir que objetos sobre ela caiam no chão.São sempre removíveis e podem apresentar regulagens na altura, profundidade e inclinação (ANTONELI, 2003).

Dos 51 equipamentos, 33 (65\%) receberam mesa, sendo que todas possuíam algum tipo de ajuste. A presença dos ajustes se justifica pela possibilidade de alterações de movimentação dos usuários, o que pode influenciar a altura da mesa durante as diferentes indicaçôes para uso.

O apoio de pés é uma base de sustentaçáo essencial para a manutenção de uma boa postura sentada e para conforto. Apresenta-se normalmente no formato individual ou em plataforma, também chamado tipo bandeja. Pode ser fixo, removível ou escamoteável, ter regulagens na altura e na profundidade. Algumas cadeiras também apresentam no apoio de pés um mecanismo que possibilita variar o posicionamento da articulação tíbiotársica, mantendo os pés em neutro ou em ligeira dorsiflexão.

O apoio de pés não é considerado acessório opcional. Como é uma peça obrigatória, todos os equipamentos veem com apoio de pés. Em casos especiais os originais precisaram ser substituídos ou modificados.

Dos 51 apoios, 24 (47\%) foram do tipo plataforma, $13(25,5 \%)$ individuais, $12(23,5 \%)$ em L e 2 (4\%) com regulagem na articulação tibiotársica. Os apoios do tipo plataforma atenderam bem às necessidades avaliadas e, assim como os individuais, alguns receberam almofadas personalizadas para acomodar deformidades dos pés ou para compensar a diferença no comprimento das pernas. Os apoios em L foram feitos sob medida e substituíram os originais. Mostraram-se eficazes no posicionamento da panturrilha, oferecendo maior área de contato e impedindo a tendência dos pés de sair do apoio e ficar atrás do mesmo. Foram feitos em madeira ou em alumínio com o revestimento, sendo mais funcionais e resistentes.

\section{Considerações finais}

A prática do seating personalizado é cada vez mais comum, principalmente quando se trata de sequelas motoras graves por paralisia cerebral. Geralmente esse tipo de equipamento é indicado para usuários que apresentam deformidades estruturadas e que não obtêm função, conforto e estabilidade postural com os sistemas disponíveis já fabricados ou em situações alternativas.

Ao analisar as indicações dos acessórios, verificou-se que mesmo equipamentos que oferecem um sistema avançado de adaptaçóes necessitam de atenção personalizada, pois é com esses ajustes que serão alcançados o conforto e a funcionalidade necessária a cada caso.

Outra observação importante a ser considerada é que o seating oferecido em fase tardia do desenvolvimento pode dificultar a adaptaçáo do paciente ao sistema devido às exigências para a correção da postura. Nesses casos em que a capacidade de resposta neuromuscular encontra-se limitada, o objetivo do seating é apenas acomodar o paciente sem correções, buscando o conforto.

É indispensável ampliar a oferta e o acesso dos pacientes à aquisição dos equipamentos apropriados e serviços especializados de adequaçáo da postura sentada, com uma formação profissional de qualidade e com o incentivo ao desenvolvimento e aplicabilidade das políticas públicas.

Observou-se que o número de equipamentos analisados é maior que o número de usuários que procuraram o serviço, porque alguns possuíam mais de uma cadeira de rodas e outros necessitaram de um novo equipamento com o passar do tempo, conforme definido em reavaliação.

A escolha de equipamentos e dispositivos no caso específico da paralisia cerebral demanda grande cuidado, bom senso, conhecimento teórico e experiência profissional.

\section{Referências}

ANTONELI, M. R. M. C. Prescrição de Cadeira de Rodas. In: TEIXEIRA, E. et al. Terapia Ocupacional na Reabilitação Física. São Paulo: Roca, 2003. p. 297-312. 
BATISTA, C. D. Tecnologia Assistiva - Equipamentos Terapêuticos Personalizados. In: LIMA, C. L. A.; FONSECA, L. F. Paralisia Cerebral: NeurologiaOrtopedia-Reabilitação. Rio de Janeiro: Guanabara Koogan, 2004. p. 447-454.

CAVAlCANTI, A.; GALVÂO, C.; CAMPOS, M. A. A. D. Cadeira de Rodas e Sistemas de Adequação Postural. In: CAVALCANTI, A.; GALVÃO, C. Terapia Ocupacional: Fundamentação e prática. Rio de Janeiro: Guanabara Koogan, 2007. p. 451-461.

COOK, A. M.; POLGAR, J. M. Cook and Hussey's Assistive Technologies: Principles and Practice. 3rd ed. New York: Mosby, 2007.

COOPER, R. A. et al. Quantifying wheelchair activity of children: a pilot study. American Journal of Physical Medicine \& Rehabilitation, Baltimore, v. 87, n. 12, p. 977-983, Dec 2008. http://dx.doi.org/10.1097/ PHM.0b013e31818dfe74

ENGSTRÖM, B. Ergonomic Seating: A True Challenge. Sweden: Vicair, 2002.

FUHRMAN, S. I.; KARG, P. E.; BERTOCCI, G. E. Effect of Wheelchair Headrest Use on Pediatric Head and Neck Injury Risk Outcomes During Rear Impact. Accident Analysis and Prevention, Elmsford, v. 40, n. 4, p. 1595-603, July 2008. http://dx.doi.org/10.1016/j. aap.2008.04.007

GIL, A. C. Como Elaborar Projetos de Pesquisa. 4. ed. São Paulo: Atlas, 2006.

LARNET, G.; EKBERG, O. Positioning improves the oral and pharyngeal swallowing function in children with cerebral palsy. Acta Paediatrica, Oslo, v. 84, n. 6, p. 689-692, June 1995. http://dx.doi. org/10.1111/j.1651-2227.1995.tb13730.x

PALISANO, R. J. et al. Effect of environmental setting on mobility methods of children with cerebral palsy. Developmental Medicine \& Child Neurology, London, v. 45, n. 2, p. 113-120, Feb 2003.

REIS, N. M. M. A Tecnologia Assistiva na Paralisia Cerebral. In: LIMA, C. L. A.; FONSECA, L. F. Paralisia Cerebral: Neurologia-Ortopedia-Reabilitação. Rio de Janeiro: Guanabara Koogan, 2004. p. 431-446.

RODBY-BOUSQUET, E.; HÄGGLUND, G. Use Of Manual And Powered Wheelchair In Children With Cerebral Palsy: A Cross-Sectional Study. BMC Pediatrics, London, v. 10, n. 59, p. 1471-2431, Aug 2010. http:// dx.doi.org/10.1186/1471-2431-10-59

SILVA, C. M.; REIS, N. M. M. Utilização da Comunicação Suplementar e/ou Alternativa na Paralisia Cerebral. In: LIMA, C. L. A.; FONSECA, L. F. Paralisia Cerebral: Neurologia-Ortopedia-Reabilitação. Rio de Janeiro: Guanabara Koogan, 2004. p. 281-288.

WRIGHT, C.; CASEY, J.; PORTER-ARMSTRONG, A. Establishing Best Practice In Seating Assessment For Children With Physical Disabilities Using Qualitative Methodologies. Disability and Rehabilitation. Assistive technology, London, v. 5, n. 1, p. 34-47, Jan 2010. http:// dx.doi.org/10.3109/17483100903137154

ZOLLARS, A.; KNEZEVICH, J. Special Seating: An Illustrated Guide. Minneapolis: Otto Bock REHA, 1996. 